\title{
ANALISIS SALURAN PEMASARAN CABAI RAWIT (Capsicum Frutescens. L) (Studi kasus di Kecamatan Kanigoro, Kabupaten Blitar)
}

Ahmad Sofanudin ${ }^{1}$ ) dan Eko Wahyu Budiman ${ }^{2)}$

1) Mahasiswa prodi Agribisnis, Fakultas Pertanian, Universitas Islam Balitar 2) Dosen prodi Agribisnis, Fakultas Pertanian, Universitas Islam Balitar

\begin{abstract}
ABSTRAK
Marketing is an economic activity which functions to deliver goods from producers to consumers. The large number in agencies marketing of Capsicum annuum will bring effect the length of the marketing chain and the cost of marketing.This research was conducted in Kanigoro District of Blitar Regency with the purpose of study marketing pattern of Capsicum annuum, analyzing marketing margin, performing function in every agency marketing and analyzing efficiency of marketing channel. Marketing of Capsicum annuum in Kanigoro sub-district consists of three marketing channels namely first channel (I); Farmer-collector-consumer. Second channel (II); Large farmer-farmer farmers-retailer-consumer farmers. The third channel (III); Big farmers-retailer-consumer farmers. The amount of marketing cost of Capsicum annuum must be issued by collecting traders $R p$ 3,000 per $\mathrm{kg}$ on channel I, traders $R p$ 3,500 per $\mathrm{kg}$ on channel II and Rp 3,500 per $\mathrm{kg}$ on channel III. The amount of profit received by the collector / middleman $R p 3,500$ per $\mathrm{kg}$ on channel I. Collector traders $R p 2.500$ per $\mathrm{kg}$, wholesalers $R p 1.500$ per $\mathrm{kg}$, retailers $R p 2,500$ per $\mathrm{kg}$ on channel II. Large traders $R p 3.500$ per $\mathrm{kg}$, retailers $R p 2,500$ per $\mathrm{kg}$ on channel III. The marketing margin value of Capsicum annuum is Rp 6,500 per $\mathrm{kg}$ on channel I, Rp 10,000 per $\mathrm{kg}$ on channel II and $\mathrm{Rp} 10,000 \mathrm{per} \mathrm{kg}$ in channel III. And share the price received by farmers amounting to 75\% on channel I, 67\% on channel II and $67 \%$ on channel III.
\end{abstract}

Keywords: Marketing channel, Marketing agency, Cost, Margin

\section{PENDAHULUAN}

Sistem pemasaran produk pertanian merupakan suatu kesatuan urutan lembaga pemasaran yang melakukan fungsi pemasaran untuk memperlancar aliran produk pertanian dari produsen awal ke tangan konsumen akhir, sebaliknya juga memperlancar aliran uang, nilai produk yang tercipta oleh kegiatan produktif yang dilakukan oleh lembaga-lembaga pemasaran. Sistem pemasaran merupakan kegiatan yang produktif yang dilakukan oleh lembaga pemasaran yang dilakukan dalam urutan horizontal maupun vertikal. Tingkat produktivitas sistem pemasaran dapat dilihat dari efisiensi dan efektifitas seluruh kegiatan fungsional pemasaran, yang juga menentukan kinerja operasi dan proses sistem. Kegiatan pemasaran pertanian tidak hanya proses pemindahan produk dari tangan petani selaku produsen ke tangan konsumen. 
Kegiatan pemasaran merupakan kegiatan yang sangat kompleks meliputi proses pengumpulan produk dari para petani, pengepakan, penyimpanan, pendistribusian, termasuk didalamnya pemilihan saluran pemasaran. Kegiatankegiatan tersebut bukan tanpa biaya. Efisiensi pemasaran dapat dinilai dari biaya akumulasi semua proses tersebut. Sistem pemasaran akan semakin efisien apabila semua kegiatan tersebut dilakukan dengan mengeluarkan biaya minimum. Sistem pemasaran yang efisien akan mendorong rendahnya margin pemasaran sehingga perbaikan pendapatan dipihak produsen, harga yang relatif murah bagi konsumen serta keuntungan yang normal bagi para pelaku kegiatan pemasaran akan tercapai. Sebuah sistem pemasaran dikatakan efisien apabila semua kegiatan pemasaran yang meliputi kegiatan pengumpulan komoditas ditingkat petani (tersebar pada daerah yang cukup luas), kemasan komoditas, transportasi, pengolahan serta distribusi (wholesaling dan retailing) berjalan dengan biaya minimum (Zahari Zen, 2010). (dari beberapa sumber/Windra)

Saluran atau rantai pemasaran cabai tergantung pada jumlah lembaga pemasaran yang terlibat dalam pemasaran dari petani produsen ke konsumennya. Perbedaan harga antara harga yang dibayarkan konsumen dengan harga yang diterima petani (marjin pemasaran) akan semakin besar apabila saluran pemasaran yang ada terlalu panjang (banyak lembaga pemasaranyangterlibat). Berdasarkan saluran pemasaran yang ada dapat diketahui posisi petani dalam tawar-menawar, yaitu dilihat dari besarnya kontribusi atau bagian harga petani terhadap harga yang dibayarkan konsumen. Jika saluran pemasaran makin panjang maka bagian harga yang diterima oleh petani semakin kecil, begitupun sebaliknya. Jika bagian yang diterima petani cukup besar, maka petani produsen yang mengusahakan cabai akan lebih mengintensifkan usahataninya.

Mengingat pentingnya sistem pemasaran dan pengetahuan saluran pemasaran cabai rawit bagi komoditas pertanian khusunya agribisnis memiliki pengaruh besar terhadap upaya peningkatan pendapatan, maka dari itu perlu melakukan kajian mengenai Analisis Saluran Pemasaran Cabai Rawit (Capsicum Frutescens.L) Di Kecamatan Kanigoro Kabupaten Blitar

\section{TUJUAN PENELITIAN}

Untuk menganalisis saluran dan margin pemasaran cabai di Kecamatan Kanigoro,pelaksanaan fungsi pada setiap lembaga pemasaran di Kecamatan Kanigoro dan efisiensi saluran pemasaran di Kecamatan Kanigoro. 


\section{METODE PENELITIAN}

\section{Analisis Lembaga Saluran Pemasaran}

Saluran pemasaran cabai rawit ditelusuri dari petani sampai ke konsumen. Pola pemasaran cabai rawit di dasarkan pada alur pemasaran yang terjadi di Kecamatan Kanigoro.

\section{Analisis Margin Pemasaran}

Analisis margin digunakan untuk mengukur jumlah keuntungan yang diperoleh masing - masing lembaga pemasaran. Dengan analisi margin juga dapat diketahui bagian (share) yang diterima petani. Secara matematis rumus analisis margin adalah :

Dimana

$$
\mathbf{M}=\mathbf{P r}-\mathbf{P f}
$$

$\mathrm{M} \quad=$ Margin Pemasaran

Pr = Harga di tingkat pengecer

Pf =Harga ditingkat petani

\section{Share Harga yang Diterima Petani}

Salah satu ukuran yang perlu diperhatikan dalam analisis margin adalah presentase bagian yang diterima produsen dari harga konsumen akhir. Untuk menentukan presentase harga yang diterima produsen dari harga konsumen akhir digunakan rumus :

$$
\text { Spf }=\frac{\text { pf }}{p r} \times 100 \%
$$

Dimana

Spf =share harga ditingkat petani

Pf = harga di tingkat petani

Pr = harga di tingkat konsumen

\section{Keuntungan lembaga pemasaran}

Untuk mengetahui jumlah keuntungan yang diperoleh masing - masing lembaga pemasaran, digunakan rumus sebagai berikut :

$$
\Pi=\mathbf{M}-\mathbf{B p}
$$

Dimana

$\Pi=$ KeuntunganLembaga Pemasaran

$\mathrm{M}=$ Margin Pemasaran

$\mathrm{Bp}=$ Biaya Penjualan 


\section{Share Biaya Pemasaran dan Share Keuntungan}

Menurut Alhusniduki (1991), share biaya pemasaran dan share keuntungan dapat pula digunakan untuk menganalisis efisiensi pemasaran dengan formulasi sebagai berikut:

Ski $=(\mathrm{Ki}) /(\mathrm{Pr}-\mathrm{Pf}) \times 100 \%$

$\mathrm{Sbi}=(\mathrm{Bi}) /(\mathrm{Pr}-\mathrm{Pf}) \times 100 \%$

Dimana

Ski = Share keuntungan ke I

Sbi = Share biaya pemasaran ke I

\section{Analisis Elastisitas Transmisi}

Kegunaan dari elastisitas transmisi adalah untuk mengetahui seberapa besar perubahan harga di pasar pengecer/pemasar/konsumen akibat terjadinya perubahan harga sebesar satu satuan unit di pasar petani/produsen. Untuk menghitung elastisitas transmisi digunakan rumus :

Dimana :

$$
E \mathbf{t}=\frac{\Delta \mathbf{P r}}{\Delta \mathbf{P f}} x \frac{\mathbf{P f}}{\mathrm{Pr}}
$$

Et = Elastisitas Transmisi Harga

$\Delta \mathrm{Pr} \quad=$ Perubahan Harga di tingkat pengecer $(\Delta \mathrm{Rp} / \Delta \mathrm{Kg})$

$\Delta \mathrm{Pf} \quad=$ Perubahan Harga di tingkat petani $(\Delta \mathrm{Rp} / \Delta \mathrm{Kg})$

Pf = Harga di tingkat petani $(\mathrm{Rp} / \mathrm{Kg})$

$\operatorname{Pr} \quad=$ Harga di tingkat pengecer $(\mathrm{Rp} / \mathrm{Kg}) \quad$ (Sudiyono, 2004)

\section{HASIL DAN PEMBAHASAN}

\section{Saluran Pemasaran}

Berdasarkan hasil penelitian mengenai saluran pemasaran cabai rawit di kecamatan kanigoro terdapat tiga saluran pemasaran yaitu:

A. Saluran pertama (I)

Petani menjual cabenya kepada petani pengumpul, kemudian petani pengumpul menjual cabenya kepada konsumen.

B. Saluran kedua (II)

Petani menjual cabenya kepada petani pengumpul, kemudian petani pengumpul menjual cabenya kepada petani besar. Petani besar menjual cabenya kepada petani pengecer dan yang terakhir petani pengecer menjual cabenya kepada konsumen. 


\section{Saluran ketiga (III)}

Petani menjual cabenya kepada petani besar, kemudian petani besar menjual cabenya kepada petani pengecer. Dan yang terakhir petani pengecer menjual cabenya kepada konsumen.

\section{Margin Pemasaran}

Saluran pemasaran I memiliki marjin sebesar Rp 6.500 per kg yang lebih rendah dari marjin Saluran pemasaran II sebesar Rp 10.000 per kg. Saluran pemasaran III sebesar Rp 10.000 per kg. Berdasarkan tinggi dan rendahnya marjin pemasaran, maka saluran pemasaran II dan III merupakan saluran pemasaran yang paling kurang efisien secara ekonomis di Kecamatan Kanigoro Kabupaten Blitar.

\section{Share Harga yang Diterima Petani}

share harga di tingkat petani pada saluran pemasaran I

$\mathrm{Spf}=\frac{R p 20.000}{R p 26.500} \times 100 \%=75 \%$

share harga di tingkat petani pada saluran pemasaran II

$\mathrm{Spf}=\frac{R p 20.000}{R p 30.000} \times 100 \%=67 \%$

share harga di tingkat petani pada saluran pemasaran II

$\mathrm{Spf}=\frac{R p 20.000}{R p 30.000} \times 100 \%=67 \%$

Dan untuk mengukur efisiensi pemasaran yang menjadi acuan yaitu dengan cara menghitung share harga yang di terima petani dengan kriteria apabila bagian yang di terima petani petani kurang dari $50 \%$ berarti pemasaran belum efisien dan bila bagian yang di terima petani petani lebih dari $50 \%$ maka pemasaran dikatakan efisien. Jadi untuk ketiga saluran pemasaran cabai rawit di Kecamatan Kanigoro semuanya efisien karena nilai share harga yang di terima petani semuanya lebih dari $50 \%$.

\section{Keuntungan lembaga pemasaran}

Pada saluran pemasaran I di ketahui

Keuntungan lembaga pemasaran $=\mathrm{Rp} 6.500-\mathrm{Rp} 3.000=\mathrm{Rp} 3.500$

Dan pada saluran pemasaran II di ketahui. Keuntungan lembaga pemasaran

Untuk pedagang pegumpul/tengkulak

$=\operatorname{Rp} 2.500-\operatorname{Rp} 0=\operatorname{Rp} 2.500$

Untuk pedagang besar

$=\operatorname{Rp} 5.000-\operatorname{Rp} 3.500=\operatorname{Rp} 1.500$

Untuk pedagang pengecer 
$=\operatorname{Rp} 2.500-\operatorname{Rp} 0=\operatorname{Rp} 2.500$

Dan pada saluran pemasaran III

Untuk pedagang besar $=\operatorname{Rp} 7.500-\operatorname{Rp} 4.000=\operatorname{Rp} 3.500$

Dan untuk pengecer $=\operatorname{Rp} 2.500-\operatorname{Rp} 0=\operatorname{Rp} 2.500$

Dari ketiga lembaga pemasaran tersebut lembaga semuanya memperoleh keuntungan untuk keberlangsungan usaha dagang cabai rawitnya. Dan keuntungan paling banyak untuk saluran pemasaran I dan III di dapat oleh pedagang pengumpul dan pedagang besar yaitu senilai $\mathrm{Rp} 3.500$ per $\mathrm{kg}$

\section{Share Biaya Pemasaran dan Share Keuntungan}

Jadi untuk Ski dan Sbi pada saluran pemasaran I

$$
\begin{array}{ll}
\text { 1. } \mathrm{Ski}=\mathrm{Rp} 3.500 /(\mathrm{Rp} 26.500-\mathrm{Rp} 20.000) \times 100 \%=53,8 \% \\
\mathrm{Sbi}=\mathrm{Rp} 3.000 /(\operatorname{Rp} 26.500-\mathrm{Rp} & 20.000) \times 100 \%=46 \%
\end{array}
$$

Dan untuk Ski dan Sbi pada saluran pemasaran II

1. $\mathrm{Ski}=\mathrm{Rp} 2.500 /(\operatorname{Rp} 30.000-\mathrm{Rp} \quad 20.000) \times 100 \%=25 \%$ Sbi $=\operatorname{Rp~0/(Rp~30.000-Rp~20.000)~x~100\% ~}=0 \%$

2. $S k i=\operatorname{Rp} 1.500 /(\operatorname{Rp} 30.000-\operatorname{Rp} 20.00) \times 100 \%=15 \%$

$$
\text { Sbi }=\operatorname{Rp} 0 /(\operatorname{Rp} 26.500-\operatorname{Rp} 20.000) \times 100 \%=0 \%
$$

3. $\mathrm{Ski}=\mathrm{Rp} 2.500 /(\operatorname{Rp} 30.000-\mathrm{Rp} 20.000) \times 100 \%=25 \%$

$$
\text { Sbi }=\operatorname{Rp~0/(Rp~30.000-Rp~20.000)~} \times 100 \%=0 \%
$$

Dan untuk Ski dan Sbi pada saluran pemasaran III

1. $S k i=R p 3.500 /(\operatorname{Rp} 30.000-R p 20.000) \times 100 \%=35 \%$ $\mathrm{Sbi}=\mathrm{Rp} 4.000 /(\mathrm{Rp} 30.000-\mathrm{Rp} 20.000) \times 100 \%=40 \%$

2. $S k i=R p 2.500 /(\operatorname{Rp} 30.000-R p 20.000) \times 100 \%=25 \%$ Sbi $=\operatorname{Rp~0/(Rp~30.000-Rp~20.000)~} \times 100 \%=0 \%$

Dalam proses pemasaran cabai rawit yang terjadi pada saluran pemasaran di Kecamatan Kanigoro bahwa share biaya terbesar terdapat pada pedagang dan share keuntungan terbesar terdapat pada pedagang pengumpul, hal ini sesuai dengan pendapat Masyrofie (1994) yang menyatakan bahwa banyak sedikitnya aktifitas fungsi pemasaran yang dilaksanakan akan mempengaruhi besar kecilnya biaya pemasaran yang dikeluarkan oleh pelaku pemasaran.

\section{Analisis Elastisitas Transmisi}

Untuk saluran pemasaran pertama $\boldsymbol{E} \mathbf{t}=\frac{\mathbf{3 3 . 0 0 0}}{\mathbf{2 3 . 0 0 0}} \boldsymbol{x} \frac{\mathbf{2 0 . 0 0 0}}{\mathbf{2 6 . 5 0 0}}=1,08$ 
Untuk saluran pemasaran kedua $\boldsymbol{E} \mathbf{t}=\frac{\mathbf{3 1 . 0 0 0}}{\mathbf{2 1 . 0 0 0}} \boldsymbol{x} \frac{\mathbf{2 0 . 0 0 0}}{\mathbf{3 0 . 0 0 0}}=0,98$

Untuk saluran pemasaran ketiga $\boldsymbol{E} \mathbf{t}=\frac{\mathbf{2 6 . 0 0 0}}{\mathbf{1 9 . 0 0 0}} \boldsymbol{x} \frac{\mathbf{2 0 . 0 0 0}}{\mathbf{3 0 . 0 0 0}}=0,91$

Dari persamaan di atas maka di dapat elastisitas transmisi harga pada saluran pemasaran I sebesar $=1,08$ berarti Et $>1$, maka laju perubahan harga di tingkat produsen. Pasar yang dihadapi oleh seluruh pelaku pasar adalah pelaku tidak sempurna, yaitu terdapat kekuatan monopoli dan oligopoli dalam sistem pemasaran tersebut serta sistem pemasaran yang berlaku belum efisien. Dan untuk saluran pemasaran yang kedua sebesar $=0,98$ berarti Et $<1$, berarti laju perubahan harga di tingkat konsumen lebih kecil dibanding dengan laju perubahan harga di tingkat produsen. Keadaan ini bermakna bahwa pemasaran yang berlaku belum efisien dan pasar yang dihadapi oleh pelaku tataniaga adalah bersaing tidak sempurna, yaitu terdapat kekuatan monopsoni atau oligopoli. Dan untuk saluran pemasaran yang ketiga sebesar $=0,91$ berarti $\mathrm{E}_{\mathrm{t}}<1$, berarti laju perubahan harga di tingkat konsumen lebih kecil dibanding dengan laju perubahan harga di tingkat produsen. Keadaan ini bermakna bahwa pemasaran yang berlaku belum efisien dan pasar yang dihadapi oleh pelaku tataniaga adalah bersaing tidak sempurna, yaitu terdapat kekuatan monopsoni atau oligopoli.

\section{KESIMPULAN DAN SARAN}

\section{Kesimpulan.}

Berdasarkan hasil penelitian mengenai saluran pemasaran cabai rawit di kecamatan kanigoro terdapat tiga saluran pemasaran yaitu:

Saluran pertama (I)

Petani menjual cabenya kepada petani pengumpul, kemudian petani pengumpul menjual cabenya kepada konsumen.

\section{Saluran kedua (II)}

Petani menjual cabenya kepada petani pengumpul, kemudian petani pengumpul menjual cabenya kepada petani besar. Petani besar menjual cabenya kepada petani pengecer dan yang terakhir petani pengecer menjual cabenya kepada konsumen.

Saluran ketiga (III)

Petani menjual cabenya kepada petani besar, kemudian petani besar menjual cabenya kepada petani pengecer. Dan yang terakhir petani pengecer menjual cabenya kepada konsumen.

Dari ketiga saluran tersebut dapat di jelaskan bahwa saluran pemasaran I di gunakan oleh 3 petani, saluran pemasaran II 9 petani dan saluran pemasaran III oleh 18 petani saluran pemasaran I memiliki marjin sebesar Rp 6.500 per $\mathrm{kg}$ yang lebih rendah dari marjin saluran pemasaran II sebesar Rp 10.000 per kg. 
Sedangkan marjin pada saluran pemasaran III yaitu sebesar Rp 10.000 per kg. Berdasarkan tinggi dan rendahnya marjin pemasaran, maka saluran pemasaran II dan III merupakan saluran pemasaran yang paling kurang efisien secara ekonomis di Kecamatan Kanigoro Kabupaten Blitar. Hal ini dikarenakan nilai harga yang di dapat petani paling tinggi. Berdasarkan hasil penelitian ketiga saluran pemasaran semuanya menguntungkan karna para petani menerima harga di atas Rp 10.000 per kg.

Berdasarkan hasil penelitian fungsi pada setiap lembaga pemasaran yaitu:

a.Pedagang Pengumpul

Pedagang yang mengumpulkan barang-barang hasil pertanian dari petani produsen dan kemudian memasarkannya kembali dalam partai besar kepada pedagang besar dan ke konsumen.

\section{b.Pedagang Besar}

Pedagang yang membeli hasil pertanian dari pedagang pengumpul/tengkulak dan atau langsung dari petani produsen, serta menjual kembali kepada pedagang pengecer/pasar dan di jual ke konsumen atau kepada pembeli untuk industri, dan pemakai usaha makanan pedas.

\section{c.Pedagang Pengecer}

Pedagang yang menjual barang hasil pertanian ke konsumen dengan tujuan memenuhi kebutuhan dan keinginan konsumen dalam partai kecil.

\section{Saran}

Hasil dari penelitian mengenai saluran pemasaran cabai rawit di Kecamatan Kanigoro, maka penulis menyampaikan beberapa saran diantaranya adalah :

1. Dengan adanya saluran-saluran pemasaran dalam memasarkan cabai rawitnya, petani dituntut untuk mempelajari secara aktif informasi pasar sehingga dapat dipilih saluran pemasaran yang lebih menguntungkan.

2. Perlu adanya bimbingan teknis dalam pertemuan kelompok tani tentang wawasan agribisnis usaha tani cabai rawit agar lebih meningkatkan pendapatan petani.

3. Pemerintah hendaknya memperhatikan dan memfasilitasi terjadinya mekanisme pasar cabai rawit agar menguntungkan semua pihak. Hal ini di tempuh dengan memberikan informasi pasar yang lebih cepat, tepat dan akurat.

\section{DAFTAR PUSTAKA}

Angraini Amaliya.(2014) "Analisis Pemasaran Cabai Merah Keriting Di Desa Sidera Kecamatan Sigi Biromaru Kabupaten Sigi” 
Arinong, A.R., dan Kadir, E. 2008. Analisis Saluran dan Margin Pemasaran Kakao di Desa Timbuseng, Kecamatan Pattalassang, Kabupaten Gowa. Jurnal Agribisnis, Vol 4 (2): 87-93.

Artha Widitananto, 2012. Analisis Pemasaran Ternak Sapi Potong. Program Studi Peternakan/ Fakultas Pertanian Universitas Sebelas Maret

Asmayanti.(2011) Sistem Pemasaran Cabai Rawit Merah (Capsicum frutescens) Di Desa Cigedug Kecamatan Cigedug Kabupaten Garut

Asrianti Evi (2013) “Analisis Pemasaran Usahatani Cabai Merah Keriting Di Desa Maku Kecamatan Dolo Kabupaten Sigi”

Daniel, M. 2002. Pengantar Ekonomi Pertanian. Bumi Aksara. Jakarta.

Daniel, Moehar., 2002, Pengantar Ekonomi Pertanian, Bumi Aksara, Jakarta

Dermawan,R dan Asep Harpenas. 2010. Budi Daya Cabai Unggul,Cabai Besar, Cabai keriting, Cabai Rawit, dan Paprika. Penebar Swadaya: Jakarta.

Gultom, H. 1996. Tataniaga Pertanian. Universitas Sumatera Utara Press. Medan

Hanafiah dan Saefuddin. 1983. Tataniaga Perikanan. Universitas Indonesia (UIPress), Jakarta.

Hanafiah, A.M. dan A.M. Saefuddin. 1986. Tataniaga Hasil Pertanian. Penerbit UI. Jakarta.

http://avansyah.blogspot.co.id/2014/08/latar-belakang-cabai-rawitmerupakan.html

Hasyim, Ali. I. 1994. Tataniaga Pertanian. Buku Ajar. Fakultas Pertanian Universitas Lampung. Bandar Lampung.

Kamaluddin, 2009. Lembaga dan Saluran Pemasaran. Erlangga. Jakarta

Kotler, P. dan K.L. Keller. 2008. Manajemen Pemasaran Edisi ke-13 Jilid 2. Erlangga, Jakarta

Laksana, 2008. Manajemen Pemasaran. Yogyakarta: Penerbit Graha

Limbong dan Sitorus (1987 Nugraha, AP. 2006. Analisis Efisiensi Saluran Pemasaran Jamur Tiram Segar di Bogor, Propinsi Jawa Barat. IPB, Fakultas Pertanian. Bogor 
Limbong dan Sitorus (1987) dalam Firdaus, Arif Maulana. 2004. Analisis Efisiensi Pemasaran Ubi Jalar Cilembu (Kasus di Desa Cilembu, Kecamatan Pamulihan, Kabupaten Sumendang, Provinsi Jawa Barat). [Skripsi]. Bogor. Departemen Ilmu-Ilmu Sosial Ekonomi Pertanian. Fakultas Pertanian. 134 hal.

Limbong, W. H dan Sitorus. P. 1987. Pengantar Tataniaga Pertanian. Bahan Kuliah Jurusan Ilmu-Ilmu Sosial Ekonomi Pertanian, Fakultas Pertanian IPB. Bogor

Mubyarto, 1984, Pengantar Ekonomi Pertanian, LP3ES,

Mubyarto, 2006, Ekonomi Pertanian, Ghalia Indonesia, Jakarta.

Ningsih Kustiawati (2011) dengan judul "Analisis Saluran Dan Marjin Pemasaran Petani Jambu Air Camplong (syzygium aqueum)"

Nugraha, (2006) dengan judul "Analisis Efisiensi Saluran Pemasaran Jamur Tiram Segar Di Bogor Provinsi Jawa Barat”

Purnama Analisis Efisiensi Ikan Hias di Desa Cibuntu. Kecamatan Cimpea. Kabupaten Bogor. Skipsi. Fakultas Pertanian Institut Pertanian Bogor. [03 Maret 2013].

Purnama, 2004 dengan judul "Analisis Efisiensi Pemasaran Ikan Hias Di Desa Cibuntu, Kecamatan Ciampea, Kabupaten Bogor".

Rahardi, F., Y.H. Indriani, dan Haryono. 1993. Agribisnis Tanaman Buah. Penebar Swadaya, Jakarta.

Rahim dan Hastuti.2007. Ekonomika Pertanian. Penebar Swadaya. Jakarta. 204

Ramadhan, W. 2009. Analisis Margin Pemasaran Sapi Potong di Kel. Singosari. Kabupaten Malang. Skripsi. STTP Malang.

Rosyid, Ali Hasyim Al. 2014. Studi Komparatif Daya Saing Cabai Merah Lahan Pasir Pantai dengan Sawah di Kabupaten Bantul. [Skripsi]. Yogyakarta. Fakultas Pertanian. Universitas Gadjah Mada. 104 hal.

Soekartawi. 1999. Agribisnis: Teori Dan Aplikasinya. Jakarta : PT. Raja Grafindo Persada.205 hal.

Sudiyono,A. 2004. Pemasaran Pertanian. Malang, UMM Press. 
Sudiyono. 2002 .Pemasaran Pertanian. Universitas Muhammadiyah Malang. Malang: UMM Press.

Suherty, dkk, (2009) dengan judul "Analisis Efisiensi Pemasaran Jeruk di Desa Karang Dukuh, Kecamatan Belawang Barito Kuala, Kalimantan Selatan".

Thamrin dan , Francis. 2012. Manajemen Pemasaran. Grafindo Persada. Jakarta.

Widiyanti, Sri. 2008. Analisis Efisiensi Pemasaran Talas (Kasus di Desa Taman Sari Kecamatan Taman Sari Kabupaten Bogor Jawa Barat). Skripsi Pada Program Sarjana Ekstensi Manajemen Agribisnis Fakultas Pertanian Institut Pertanian Bogor. Bogor.

Winardi, 1989, Strategi Pemasaran (Marketing Strategy), Bandung: Mandar Маји

Yudhit Restika Putri, Siswanto Imam Santoso, Wiludjeng Roessali (2014) dengan judul Farmer Share Dan Efisiensi Saluran Pemasaran Kacang Hijau (Vigna Radiata, L.)

Zen, Zahari. 2010. Mengukur Efisiensi Produk Agribisnis. http//xa.yimg.com. 